\title{
Photoprotective Activity of Lichen Extracts and Isolated Compounds in Parmotrema Tinctorum
}

\section{Tram Thi Thu Nguyen $\left.{ }^{1, *} \mathbb{(}\right)$, Trinh Thi Diem Vo ${ }^{2 \mathbb{C}}$, Yen Hoang Tran ${ }^{3 \mathbb{C}}$, Dat Tuan Truong ${ }^{3 \mathbb{C}}$, Duy Chi Phan ${ }^{3(\mathbb{D})}$, Phuoc Huu Le ${ }^{4(\mathbb{D})}$}

1 Department of Chemistry, Faculty of Sciences, Can Tho University of Medicine and Pharmacy, 179 Nguyen Van Cu, Can Tho 94000, Vietnam

2 College of Natural Science, Can Tho University, 3-2 Road, Can Tho City 94000, Vietnam; trinhdiemtv1997@gmail.com (T.T.D.V.);

3 Faculty of Pharmacy, Can Tho University of Medicine and Pharmacy, 179 Nguyen Van Cu, Can Tho 94000, Vietnam; thyen@ctump.edu.vn (Y.H.T.); 1853030015@student.ctump.edu.vn (D.T.T.); 1853030013@student.ctump.edu.vn (D.C.P.);

4 Department of Physics and Biophysics, Faculty of Sciences, Can Tho University of Medicine and Pharmacy, 179 Nguyen Van Cu, Can Tho 94000, Vietnam; lhuuphuoc@ctump.edu.vn (P.H.L.);

* Correspondence: ntttram@ctump.edu.vn (T.T.T.N.);

Received: 29.12.2020; Revised: 18.01.2021; Accepted: 23.01.2021; Published: 31.01.2021

\begin{abstract}
Lichens are an excellent source for the discovery and development of new photoprotective compounds. However, investigation on their bioactivities remains limited, especially in Vietnam. In this study, six lichen extracts (Parmotrema poolii, P. sancti-angelii, P. tinctorum, Usnea baileyi, $U$. pulvinulata, $U$. undulata) and five isolated compounds from commonly distributed species $P$. tinctorum (methyl $\beta$-orcinol carboxylate (1), atranorin (2), lecanorol (3), salazinic acid (4), $1 \beta$-acetoxyhopan$3 \beta, 22$-diol (5)) have been screened in vitro for their photoprotective activity. The photoprotective potential was investigated by determination of their absolute (UV-PF, $\lambda c$, UVA-PF) and relative indexes (SUI, ISP). The structures of isolated compounds were elucidated by spectroscopic methods and confirmed by X-ray diffraction. The results showed that $P$. poolii, P. sancti-angelii, $P$. tinctorum, $U$. baileyi, $U$. undulata, and compounds of methyl $\beta$-orcinol carboxylate (1) and salazinic acid (4) acted as strict UVB filters, and their photoprotective activities are comparable to that of the commercial UVB filter (4-methylbenzylidene camphor). Meanwhile, U. pulvinulata acted as a UVA booster. Compound (3) presented characteristics of a UVA filter, (2) protected well from both UVA and UVB while (5) exhibited a weak photoprotective activity. For the first time, this work successfully extracted several highly potential solar photoprotective compounds from Vietnam's lichens.
\end{abstract}

Keywords: Lichen; Parmotrema; photoprotection; Usnea; UV filter.

(c) 2021 by the authors. This article is an open-access article distributed under the terms and conditions of the Creative Commons Attribution (CC BY) license (https://creativecommons.org/licenses/by/4.0/).

\section{Introduction}

The increase in solar UV radiation on the Earth's surface is now considered a major deleterious environmental factor to sun-exposed organisms [1,2]. Due to its harmful effects, the search for new sunscreens still needs to be actively continued. Recently, there is a considerable amount of study aiming to discover and develop new sunscreen metabolites from natural sources, including animals, plants, and lichens [3-5]. Lichens are stable, consistent, and identifiable mutualistic associations between algae and/or cyanobacteria (the photobiont) and fungi (the mycobiont) and dedicated bacterial communities [6,7]. By the year 2000, the number 
of lichen species was recorded to be 13,500 to 30,000 . With the expansion of investigation scope and development of sequencing methods, such number may increase reasonably [8]. Thanks to this association, lichens can survive under extreme ecological conditions, such as intense UV radiation, extreme temperatures, desiccation, etc. [9-12]. In terms of UV radiation, lichens have developed various photoprotect mechanisms such as screening, quenching, and repair mechanisms [13,14]. An important protective mechanism of lichens is the production of UV screening compounds, such as phenolic compounds (depsides, depsidones, diphenyl ethers), anthraquinones, xanthones, or shikimic acid derivatives (calycin, mycosporines, scytonemin) [15-18]. Compounds isolated from lichens have been suggested as potential UV blockers due to their absorption on the UV region and their antioxidant activity and photostability [19-24]. Moreover, some isolates with complex structures required a long and complicated synthesis. Therefore, natural products are an important source for the discovery of new UV protectants. In this study, the photoprotective potential of six lichen extracts and five isolated metabolites were investigated by a simple and inexpensive method based on their absolute (UV-PF, $\lambda c$, UVA-PF) and relative indexes (SUI, ISP), which were considered by cosmetic organizations. As a preliminary conclusion, Vietnamese lichens were confirmed as a promising source of photoprotective compounds.

\section{Materials and Methods}

\subsection{Lichen material.}

Parmotrema poolii, P. sancti-angelii, P. tinctorum, Usnea baileyi, U. pulvinulata, and U. undulata were collected in Lam Dong province, Vietnam, in December 2019. The identification was conducted by Dr. Kawinnat Buaruang (Lichen herbarium of Ramkhamhaeng University, Department of Biology, Faculty of Science, Ramkhamhaeng University, Thailand). The voucher specimens were deposited in the herbarium of the Department of Chemistry, Faculty of Science, Can Tho University of Medicine and Pharmacy, Can Tho City, Vietnam.

\subsection{General experimental procedures.}

The NMR experiments were performed on Bruker DMX 300 and 500 spectrometers. UV spectra were recorded on a Hitachi U-2900 spectrophotometer.

Column chromatography was performed on normal phase silica gel (40-63 $\mu \mathrm{m}$, Keselgel 60, Merck 7667). Thin-layer chromatography was performed on Kieselgel 60F254 plates (Merck), and spots were visualized under UV light or sprayed with vanillin $(0.5 \mathrm{~g}$ vanillin in $80 \mathrm{~mL}$ sulfuric acid and $20 \mathrm{~mL}$ ethanol), and then heated at $120^{\circ} \mathrm{C}$. All commercial UV filters were purchased from Sigma Aldrich. To prepare the O/W emulsion, double-distilled water was used. All solvents for extraction used were purchased from Chemsol, purity $\geq 99.0$ $\%$.

X-ray structure determination was performed using a RIGAKU XtaLabPro diffractometer equipped with a Mo microfocus sealed tube generator coupled to a doublebounce confocal Max-Flux ® multilayer optic and an HPAD PILATUS3 R 200K detector. Data collection and reduction were carried out using CrysaliPro. The structure was also solved by intrinsic phasing methods and refined by full-matrix least-squares methods on 140 parameters, weighted refinement: $w=1 /\left[\sigma^{2}\left(\mathrm{~F}_{\mathrm{o}}^{2}\right)+(0.0850 \mathrm{P})^{2}\right]$ where $\mathrm{P}=\left[\max \left(\mathrm{F}_{\mathrm{o}}^{2}, 0\right)+2 \mathrm{~F}_{\mathrm{c}}^{2}\right] / 3$. 


\subsection{Extraction and isolation.}

To obtain the crude extracts, the ground air-dried thalli of each lichen $(5 \mathrm{~g})$ were extracted with $30 \mathrm{~mL}$ a mixture of acetone-dichloromethane (1:1) by maceration for $4 \mathrm{~h}$ at room temperature with sonication for 30 minutes. After evaporating the solvents under reduced pressure, the crude extracts were obtained.

To isolate the main secondary metabolites of $P$. tinctorum, $200 \mathrm{~g}$ of the dried, crushed material were successively and exhaustively extracted with 2 liters of a mixture of acetonedichloromethane $(1: 1)$ by a hot Soxhlet to give acetone-dichloromethane extract. When the extract was evaporated under reduced pressure, a precipitate occurred and was filtered off (1.5 g). After re-crystallized, the precipitate was subjected to a silica gel column and eluted with $n$ hexane-ethyl acetate 95:5 to yield atranorin $(2,6.5 \mathrm{mg})$. The rest of the extract was then subjected to silica gel column chromatography and eluted by the solvent system of petroleum ether-ethyl acetate with increasing ethyl acetate ratios to obtain five fractions from Ac1 to Ac5. The fraction Ac3 was subjected to a silica gel column and eluted with $n$-hexane- ethyl acetate with increasing ethyl acetate ratios to yield methyl $\beta$-orcinol carboxylate $(1,5.9 \mathrm{mg}), 1 \beta$ acetoxyhopan-3 $\beta, 22$-diol (5, $4.5 \mathrm{mg})$, lecanorol (3, $7.1 \mathrm{mg})$ and salazinic acid (4, $8.3 \mathrm{mg})$.

Compound 1: colourless needles (acetone); ${ }^{1} \mathrm{H} \mathrm{NMR}\left(\mathrm{CDCl}_{3}, 300 \mathrm{MHz}\right) \delta_{\mathrm{H}}(\mathrm{ppm}) 2.10$ $\left(3 \mathrm{H}, s, 8-\mathrm{CH}_{3}\right), 2.46\left(3 \mathrm{H}, s, 9-\mathrm{CH}_{3}\right), 3.92\left(3 \mathrm{H}, s,-\mathrm{COOCH}_{3}\right), 5.09(1 \mathrm{H}, s, 4-\mathrm{OH}), 6.21(1 \mathrm{H}, s$, $\mathrm{H}-5), 12.05(1 \mathrm{H}, s, 2-\mathrm{OH}) ;{ }^{13} \mathrm{C} \mathrm{NMR}\left(\mathrm{CDCl}_{3}, 75 \mathrm{MHz}\right) \delta_{\mathrm{C}}(\mathrm{ppm}) 105.4(\mathrm{C}-1), 158.1(\mathrm{C}-2)$, 108.6 (C-3), 163.3 (C-4), 110.7 (C-5), 140.3 (C-6), 172.7 (C-7), 7.8 (C-8), 24.2 (C-9), 52.0 ($\left.\mathrm{COOC}_{3}\right)$.

Compound 2: colorless powder; ${ }^{1} \mathrm{H}$ NMR (DMSO-d6, $\left.500 \mathrm{MHz}\right) \delta_{\mathrm{H}}(\mathrm{ppm}) 10.52(1 \mathrm{H}$, $s, 2-\mathrm{OH}), 10.21$ (1H, s, 3-CHO), 6.41 (1H, s, H-5), 2.35 (3H, s, H-8), 6.65 (1H, s, H-5'), 2.04 $\left(3 \mathrm{H}, s, \mathrm{H}-8^{\prime}\right), 2.39$ (3H, s, H-9'), $3.88\left(3 \mathrm{H}, s, 7^{\prime}-\mathrm{OC}_{3}\right) ;{ }^{13} \mathrm{C}$ NMR (DMSO-d $\left.6,125 \mathrm{MHz}\right) \delta_{\mathrm{C}}$ (ppm) 107.9 (C-1), 163.6 (C-2), 109.0 (C-3), 161.7 (C-4), 115.2 (C-5), $151.4(\mathrm{C}-6), 164.5$ (C7), 193.8 (C-8), 20.1 (C-9), 110.6 (C-1'), 157.4 (C-2'), 116.3 (C-3'), 148.8 (C-4'), 115.7 (C-5'), 136.5 (C-6'), 169.7 (C-7'), $9.3\left(\mathrm{C}^{-8}{ }^{\prime}\right), 21.1\left(\mathrm{C}-9\right.$ '), $52.3\left(7^{\prime}-\mathrm{OCH}_{3}\right)$.

Compound 3: red needles (acetone); ${ }^{1} \mathrm{H}$ NMR (MeOD, $\left.300 \mathrm{MHz}\right) \delta_{\mathrm{H}}(\mathrm{ppm}) 2.27(3 \mathrm{H}$, $s, \mathrm{H}^{-7}$ '), 2.54 (3H, s, H-8), 6.19 (1H, brs, H-3); 6.26 (1H, brs, H-5), 6.40 (1H, brs, H-3'), 6.46 (1H, brs, H-5'), 6.53 (1H, brs, H-1'); ${ }^{13} \mathrm{C}$ NMR (MeOD, $\left.75 \mathrm{MHz}\right) \delta_{\mathrm{c}}(\mathrm{ppm}) 105.1$ (C-1), 164.4 (C-2), 101.8 (C-3), 166.8 (C-4), 112.9 (C-5), 144.7 (C-6), 171.5 (C-7), 24.4 (C-8), 114.8 (C1'), 159.4 (C-2'), 107.4 (C-3'), 152.3 (C-4'), 114.5 (C-5'), 141.6 (C-6'), 21.4 (C-7').

Compound 4: colourless needles (acetone); ${ }^{1} \mathrm{H}$ NMR (DMSO- $d_{6}, 300 \mathrm{MHz}$ ) $\delta_{\mathrm{H}}(\mathrm{ppm})$ $2.45\left(3 \mathrm{H}, s, 9-\mathrm{CH}_{3}\right), 4.64\left(2 \mathrm{H}, s, 8^{\prime}-\mathrm{CH}_{2}-\right), 6.79$ (1H, brs, H-9'), $6.88(1 \mathrm{H}, s, \mathrm{H}-5), 8.29(1 \mathrm{H}$, brs, 4-OH), 10.48 (1H, s, 8-CHO), $12.06(1 \mathrm{H}, b r s, 2-\mathrm{OH}) ;{ }^{13} \mathrm{C}$ NMR (DMSO-d6, $\left.75 \mathrm{MHz}\right) \delta_{\mathrm{C}}$ (ppm) 111.9 (C-1), 165.9 (C-2), 110.7 (C-3), 164.0 (C-4), 117.4 (C-5), 152.8 (C-6), 160.3 (C7), 192.7 (C-8), 21.4 (C-9), 109.6 (C-1'), 152.2 (C-2'), 123.5 (C-3'), 148.2 (C-4'), 137.3 (C-5'), $\left.138.1\left(\mathrm{C}-6^{\prime}\right), 163.5\left(\mathrm{C}-7^{\prime}\right), 52.6\left(\mathrm{C}-8^{\prime}\right), 94.8\left(\mathrm{C}^{-9}\right)^{\prime}\right)$.

Compound 5: colorless powder; CCDC 1811397 contains the supplementary crystallographic data for this paper. The data can be obtained free of charge from The Cambridge Crystallographic Data Centre via www.ccdc.cam.ac.uk/data_request/cif.

\subsection{Determination of photoprotective activity.}

The photoprotective activity was determined according to the method of Legouin [25] with some modifications. Briefly, the oil/water $(\mathrm{O} / \mathrm{W})$ emulsion was prepared by dissolving 10 
$\mathrm{g}$ of a sodium dodecyl sulfate solution (SDS) $10 \%$ in $20 \mathrm{~g}$ of distilled water. After vigorous mixing in a blender, $10 \mathrm{~g}$ of liquid paraffin was incorporated to obtain a homogeneous emulsion. The test samples were added to $\mathrm{O} / \mathrm{W}$ emulsion at $10 \%(w / w)$ concentration. A final test sample concentration of $20 \mu \mathrm{g} / \mathrm{mL}$ was observed by dilution in ethanol. Three commercial UV filters (4-methylbenzylidene camphor (4-MBC)), Avobenzone, and Octocrylene were used as positive controls. Absorbance $\left(\mathrm{A}_{\lambda}\right)$ measurements between 290 and $400 \mathrm{~nm}$ corresponding to UV region were recorded. The experimental data were transferred into an Excel spreadsheet specially arranged for calculation. Transmittance $\left(T_{\lambda}\right)$ was calculated from absorbance. The experimental values resulted directly in both UV-PF and UVA-PF values, the critical wavelength $\left(\lambda_{c}\right)$ [26], the UVA-PF/UV-PF ratio, the Spectral Uniformity Index (SUI) [27] and the Ideal Spectral Profile (ISP) [28]. UV-PF values are the means of different values calculated from $\left(E_{\lambda} \times I_{\lambda}\right)$ relative to Mexico, Melbourne, COLIPA International 2006, and COLIPA UVA 2007. All tests were done in duplicate, and the results averaged.

$$
\begin{aligned}
& \mathrm{A}(\lambda)=10^{-\mathrm{T}} \\
& \mathrm{UV}-\mathrm{PF}=\frac{\sum_{290}^{400} E_{\lambda} I_{\lambda} \Delta_{\lambda}}{\sum_{290}^{400} E_{\lambda} I_{\lambda} T_{\lambda} \Delta_{\lambda}} \\
& \mathrm{UVA}-\mathrm{PF}=\frac{\sum_{320}^{400} E_{\lambda} I_{\lambda} \Delta_{\lambda}}{\sum_{320}^{400} E_{\lambda} I_{\lambda} T_{\lambda} \Delta_{\lambda}}
\end{aligned}
$$

$\mathrm{E}_{\lambda}$ is the spectral irradiation of terrestrial sunlight at $\lambda, \mathrm{I}_{\lambda}$ is the erythemal action spectrum at $\lambda$ and $\mathrm{T}_{\lambda}$ is the spectral transmittance of the sample at $\lambda$.

$$
\begin{aligned}
& \lambda_{C}=0.9 \int A(\lambda) d \lambda \\
& \text { UVA/UVB ratio }=\frac{\int A(\lambda) d \lambda / \int d \lambda}{\int A(\lambda) d \lambda / \int d \lambda} \\
& S U I=\frac{\sum_{290}^{380} A_{\lambda}}{\sum_{290}^{380}\left|A_{\lambda}-\bar{A}\right|} \\
& \mathrm{ISP}=\frac{\sum_{290}^{400}\left|\mathrm{~A}_{\lambda}-\hat{\mathrm{A}}_{\lambda}\right|}{\sum_{290}^{400} \mathrm{~A}_{\lambda}} \times 100
\end{aligned}
$$

where $A_{\lambda}$ is the spectral absorbance at $\lambda$ and $\hat{A}_{\lambda}$ is the ideal spectral absorbance at $\lambda . \hat{A}_{\lambda}$ is equal to the mean absorbance between 290 and $385 \mathrm{~nm}$ for all wavelengths in this spectral interval. Between 385 and $400 \mathrm{~nm}, \hat{\mathrm{A}}_{\lambda}$ is given as:

$$
\hat{\mathrm{A}}_{\lambda}=\mathrm{A}_{385} \mathrm{x} \frac{400-\lambda}{15}
$$




\section{Results and Discussion}

General extraction yields varied between $7.2 \%$ and $12.4 \%$, in which $P$. tinctorum possessed the highest one. With an extractable yield higher than $10 \%(\mathrm{w} / \mathrm{w})$, such species were interested in industrial use. In this study, a mixture of acetone-dichloromethane (1:1) was used to extract a great variety of metabolites, which have been considered clearly as lichen UVprotectant metabolites [29]. The results suggested that $P$. tinctorum contained more photoprotective ingredients than five other species. Besides collection with suitable quantity, a study on phytochemical constituents of $P$. tinctorum was conducted to obtain compounds involved in the photoprotective activity. From acetone-dichloromethane extract, five compounds were isolated and determined structures, including one monocyclic aromatic compound (methyl $\beta$-orcinol carboxylate 1), two depsides (atranorin 2, lecanorol 3), one depsidone (salazinic acid 4) and one triterpenoid (1 $\beta$-acetoxyhopan-3 $\beta, 22$-diol 5 ). Their structures were elucidated by spectroscopic data and compared with those in references [3032]. The absolute configuration of 5 was confirmed as $\mathrm{C} 1 R, \mathrm{C} 3 S, \mathrm{C} 5 S, \mathrm{C} 8 R, \mathrm{C} 9 S, \mathrm{C} 10 R$, $\mathrm{C} 13 R, \mathrm{C} 14 R, \mathrm{C} 17 \mathrm{~S}, \mathrm{C} 18 S, \mathrm{C} 21 S$. Here, the absolute configuration of (5) was elucidated unambiguously by X-ray diffraction for the first time (Figure 1).<smiles>COC(=O)c1c(C)cc(O)c(C)c1OC(=O)c1c(C)cc(O)cc1OC(=O)c1c(C)cc(O)c(C)c1OC(=O)c1c(C)cc(O)c(C)c1O</smiles>

Methyl $\beta$-orcinol carboxylate 1

Atranorin 2

Lecanorol 3
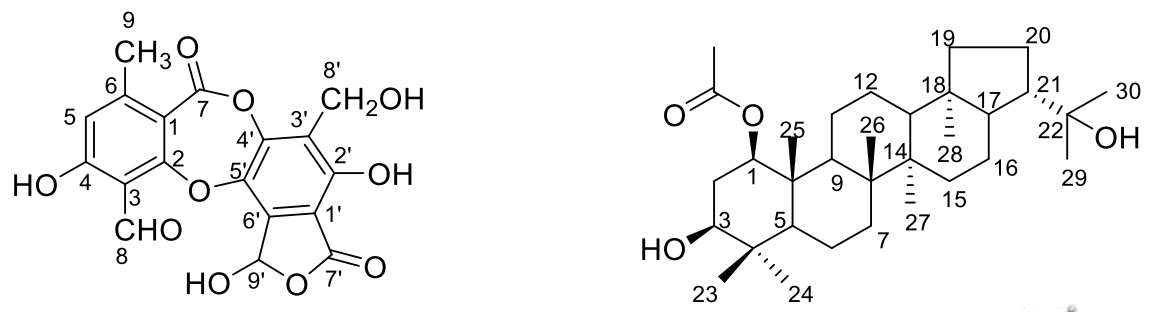

Salazinic acid 4

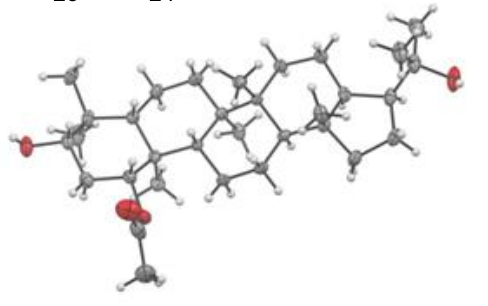

$1 \beta$-Acetoxyhopan-3 $\beta, 22$-diol 5

Figure 1. Structures of isolated compounds in P. tinctorum.

The photoprotective effects of lichen extracts and isolated compounds were evaluated on absolute (UV-PF, $\lambda c$, UVA-PF) and relative indexes (SUI, ISP), which were mentioned by cosmetic organizations. The absorbance was recorded between $290-400 \mathrm{~nm}$, corresponding to the UVB and UVA regions. Based on the values obtained with commercial organic filters, a decision tree was created to classify the filters. Figure 2 presented that the extracts of $P$. poolii, $P$. sancti-angelii, $P$. tinctorum, $U$. baileyi, and $U$. undulata exhibited a maximal absorbance in the region of UVB $(290-320 \mathrm{~nm})$ similar to the reference compound 4-MBC, while $U$. 
pulvinulata showed a maximal absorbance in the region of UVA (320-400 nm) similar to positive UVA filter Avobenzone (Figure 2).

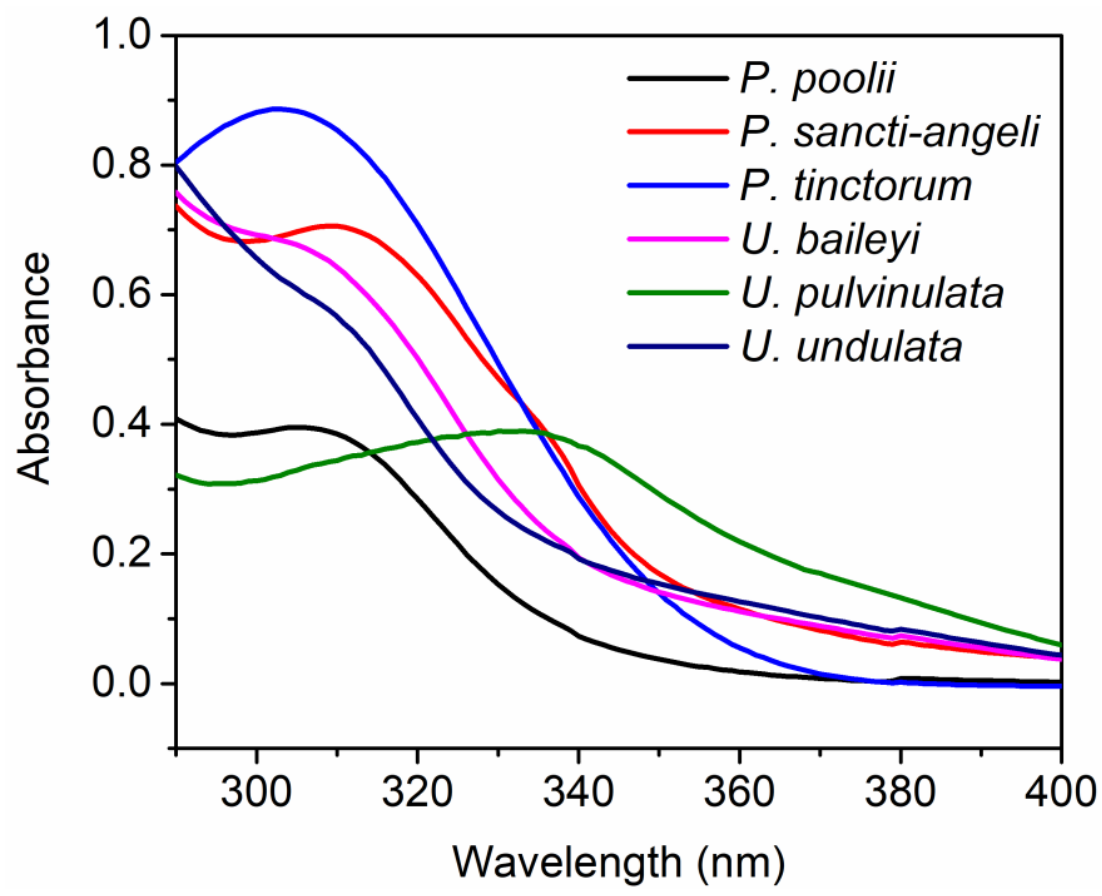

Figure 2. The UV absorption profiles of six lichen extracts.

According to the values obtained in Table 1 and decision tree for predicting the UV protection range in Figure 3 [25], the extracts of $P$. poolii, $P$. sancti-angelii, $P$. tinctorum, $U$. baileyi, U. undulata, and compounds (1), (4) were suggested as strict UVB filters. With the values UV-PF $>1.5, \lambda_{c}>370 \mathrm{~nm}$, UVA-PF $<2$, U. pulvinulata was suggested as UVA booster. Compound (3) exhibited as a UVA blocker, while compound (2) was categorized as (UVA + UVB) blocker. Compound (5) with the triterpenoid skeleton was classified in the rejected group due to the value UV-PF $<1.5$. The results completely agreed with natural UV protectants' chemical features as the normal presence of unsaturated bonds in conjugated systems [15].

Table 1. Absolute, relative indexes of the extracts and compounds compared to three commercialized UV filters.

\begin{tabular}{|c|c|c|c|c|c|}
\hline Extracts/Compounds & UV-PF & $\lambda_{\mathrm{c}}$ & UVA-PF & SUI & ISP \\
\hline P. poolii & 3.0 & 337 & 1.5 & 1.3 & 100.4 \\
\hline P. sancti-angeli & 4.1 & 353 & 1.9 & 1.7 & 99.7 \\
\hline P. tinctorum & 2.1 & 335 & 1.2 & 1.2 & 99.4 \\
\hline U. baileyi & 3.6 & 358 & 1.6 & 1.5 & 98.3 \\
\hline U. pulvinulata & 2.2 & 374 & 1.9 & 1.4 & 94 \\
\hline U. undulata & 3.1 & 363 & 1.6 & 1.6 & 97.1 \\
\hline $\begin{array}{l}\text { Methyl } \beta \text {-orcinol carboxylate } \\
\text { (1) }\end{array}$ & 4.0 & 320 & 1.1 & 0.9 & 110.5 \\
\hline Atranorin (2) & 1.7 & 376 & 1.2 & 1.6 & 87.9 \\
\hline Lecanorol (3) & 4.0 & 382 & 2.6 & 3.3 & 92.7 \\
\hline Salazinic acid (4) & 2.7 & 338 & 1.4 & 1.3 & 103.9 \\
\hline $\begin{array}{l}\text { 1 } \beta \text {-Acetoxyhopan-3 } \beta, 22 \text {-diol } \\
\text { (5) }\end{array}$ & 1.0 & 392 & 0.9 & -0.6 & -668 \\
\hline $4-\mathrm{MBC}^{a}$ & 13.1 & 330 & 1.7 & 0.9 & 105.0 \\
\hline Avobenzone $^{b}$ & 9.6 & 379 & 107.5 & 3.0 & 99.8 \\
\hline Octocrylene $^{c}$ & 5.0 & 339 & 1.8 & 1.4 & 89.0 \\
\hline
\end{tabular}

UV-PF: UV Protection Factor, UVA-PF: UVA Protection Factor, $\lambda_{c}$ : critical wavelength. SUI: Spectral Uniformity Index, ISP: Ideal Spectral Profile $a, b$, and $c$ : commercial UVB, UVA, and (UVA+UVB) filters. 


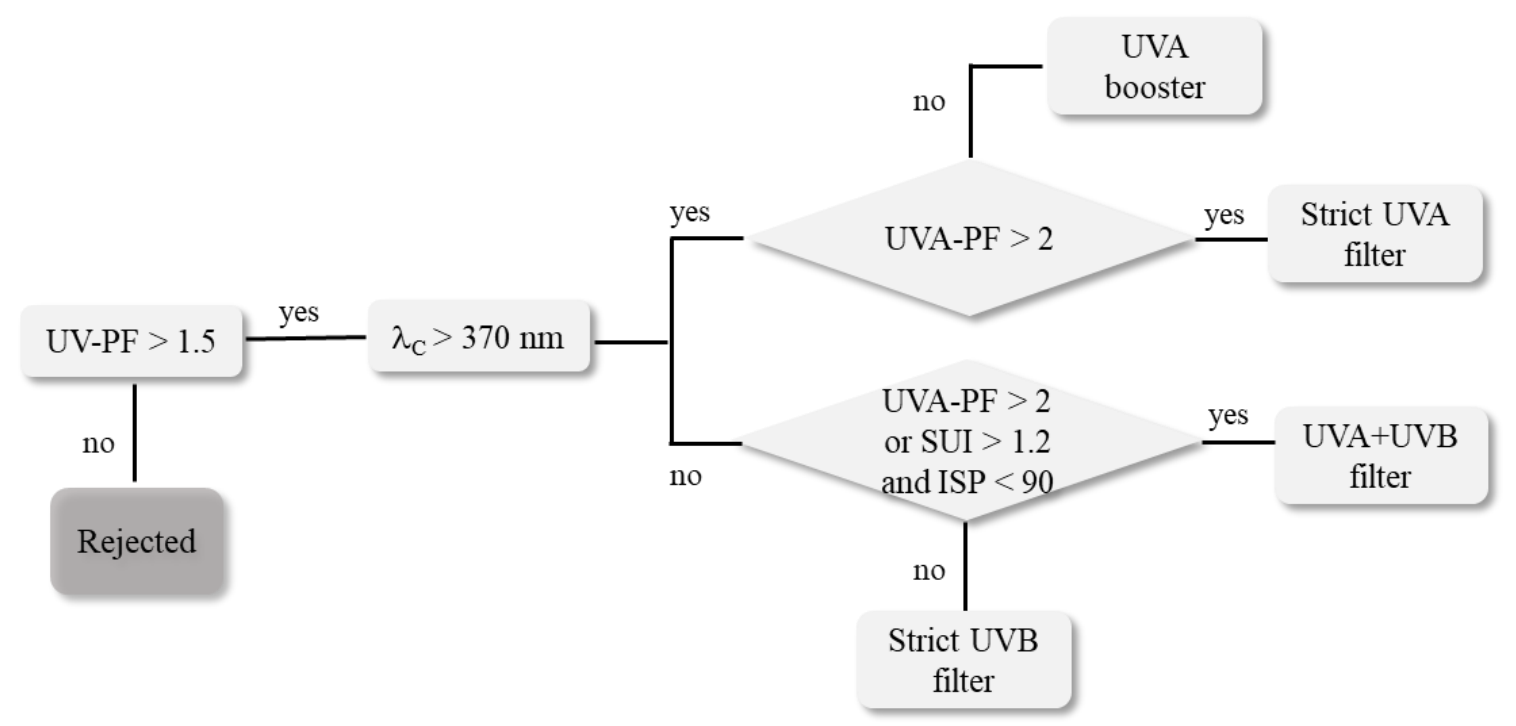

Figure 3. Decision tree for predicting the UV protection range. Reproduced from Ref. [25] (CC BY).

Here, the in vitro method for screening samples' photoprotective activity overcomes some disadvantages due to its simplicity and inexpensiveness. Moreover, all these in vitro methods so far required an amount of active raw material generally than $100 \mathrm{mg}$ and prevented the evaluation of samples in minute amounts [25]. This method appeared to be a better choice for screening the photoprotective effect of natural products that were usually isolated in small quantities.

So far, UVB protection is urgent, and UVA protection is now considered to be equally essential. Our study confirmed that lecanorol could be a good UVA filter candidate. Besides, atranorin has been reported to act as UV filters. An increasing accumulation of such metabolite in Cladonia rangiferina has been observed under high light intensities supplemented by UVA and UVB [15]. Although salazinic acid had no high SPF value, this depsidone was used as a UVA booster [29]. Its strong absorption could explain the accumulation of these compounds in P. tinctorum extract in the UV region.

\section{Conclusions}

This work showed a new solar photoprotective approach of Vietnamese lichens. The extracts of $P$. poolii, $P$. sancti-angelii, $P$. tinctorum, $U$. baileyi, and $U$. undulata were categorized as UVB blockers, while $U$. pulvinulata was suggested as UVA booster. The presence of methyl $\beta$-orcinol carboxylate, atranorin, lecanorol, and salazinic acid explained partly higher UV absorption of $P$. tinctorum. Further studies on photostability and phototoxicity of extracts and isolates should be continued for potential cosmetic application as sunscreen.

\section{Fundings}

This research received no external funding.

\section{Acknowledgments}

We are grateful to Dr. Nguyen Thanh Binh and Dr. Retailleau P., ICSN, CNRS, France, to support X-ray structural determination. 


\section{Conflicts of Interest}

The authors declare no conflict of interest.

\section{References}

1. Rastogi, R.P.; Incharoensakdi, A. UV radiation-induced biosynthesis, stability and antioxidant activity of mycosporine-like amino acids (MAAs) in a unicellular cyanobacterium Gloeocapsa sp. CU2556. J. Photochem. Photobiol. B: Biol. 2014, 130, 287-292, https://doi.org/10.1016/j.jphotobiol.2013.12.001.

2. Schneider, G.; Figueroa, F.L.; Vega, J.; Chaves, P.; Álvarez-Gómez, F.; Korbee, N.; Bonomi-Barufi, J. Photoprotection properties of marine photosynthetic organisms grown in high ultraviolet exposure areas: Cosmeceutical applications. Algal Research 2020, 49, 101956, https://doi.org/10.1016/j.algal.2020.101956.

3. Mouffouk, C.; Mouffouk, S.; Oulmi, K.; Mouffouk, S.; Haba, H. In vitro photoprotective, hemostatic, antiinflammatory and antioxidant activities of the species Linaria scariosa Desf. S. Afr. J. Bot. 2020, 130, 383388, https://doi.org/10.1016/j.sajb.2020.01.003.

4. Twilley, D.; Moodley, D.; Rolfes, H.; Moodley, I.; McGaw, L.J.; Madikizela, B.; Summers, B.; Raaff, L.-a.; Lategan, M.; Kgatuke, L.; Mabena, E.C.; Lall, N. Ethanolic extracts of South African plants, Buddleja saligna Willd. and Helichrysum odoratissimum (L.) Sweet, as multifunctional ingredients in sunscreen formulations. S. Afr. J. Bot. 2021, 137, 171-182, https://doi.org/10.1016/j.sajb.2020.10.010.

5. He, h.; Li, a.; Li, s.; Tang, j.; Li, l.; Xiong, l. Natural components in sunscreens: Topical formulations with sun protection factor (SPF). Biomed. Pharmacother. 2021, 134, 111161, https://doi.org/10.1016/j.biopha.2020.111161.

6. Molins, A.; Chiva, S.; Calatayud, Á.; Marco, F.; García-Breijo, F.; Reig-Armiñana, J.; Carrasco, P.; Moya, P. Multidisciplinary approach to describe Trebouxia diversity within lichenized fungi Buellia zoharyi from the Canary Islands. Symbiosis 2020, 82, 19-34, https://doi.org/10.1007/s13199-020-00722-8.

7. Furmanek, L.; Czarnota, P; Seaward, M.R.D. Antifungal activity of lichen compounds against dermatophytes: a review. J Appl Microbiol. 2019, 127, 308-325, https://doi.org/10.1111/jam.14209.

8. Zhao, Y.; Wang, M.; Xu, B. A comprehensive review on secondary metabolites and health-promoting effects of edible lichen. J. Funct. Foods 2020, 19, 104283, https://doi.org/10.1016/j.jff.2020.104283.

9. Rassabina, A.E.; Gurjanov, O.P.; Beckett, R.P.; Minibayeva, F.V. Melanin from the Lichens Cetraria islandica and Pseudevernia furfuracea: Structural Features and Physicochemical Properties. Biochemistry (Moscow) 2020, 85, 623-628, https://doi.org/10.1134/S0006297920050119.

10. Váczi, P.; Gauslaa, Y.; Solhaug, K.A. Reprint of Efficient fungal UV-screening provides a remarkably high UV-B tolerance of photosystem II in lichen photobionts. Plant Physiol. Biochem. 2019, 134, 123-128, https://doi.org/10.1016/j.plaphy.2018.09.030.

11. González-Burgos, E.; Fernández-Moriano, C.; Gómez-Serranillos, M.P. Current knowledge on Parmelia genus: Ecological interest, phytochemistry, biological activities and therapeutic potential. Phytochemistry 2019, 165, 112051, https://doi.org/10.1016/j.phytochem.2019.112051.

12. Ranjit, R.; Paudel, S.; Shrestha, R.; Maharjan, J.; Devkota, B.D.; Bhattarai, S.; Pandey, B.P. Biological and Chemical Analysis of Five Selected Lichen Species from Sagarmatha National Park of Nepal. Trop J Nat Prod Res. 2020, 4(2), 43-49, https://doi.org/doi.org/10.26538/tjnpr/v4i2.4.

13. Carreto, J.I.; Carignan, M.O. Mycosporine-like amino acids: relevant secondary metabolites. Chemical and ecological aspects. Mar. Drugs 2011, 9, 387-446, https://doi.org/10.3390/md9030387.

14. Cho, S.M.; Lee, H.; Hong, S.G.; Lee, J. Study of Ecophysiological Responses of the Antarctic Fruticose Lichen Cladonia borealis Using the PAM Fluorescence System under Natural and Laboratory Conditions. Plants 2020, 9, 85, https://doi.org/10.3390/plants9010085.

15. Nguyen, K.-H.; Chollet-Krugler, M.; Gouault, N.; Tomasi, S. UV-protectant metabolites from lichens and their symbiotic partners. Nat. Prod. Rep. 2013, 30, 1490-1508, https://doi.org/10.1039/c3np70064j.

16. Lalegerie, F.; Lajili, S.; Bedoux, G.; Taupin, L.; Stiger-Pouvreau, V.; Connan, S. Photoprotective compounds in red macroalgae from Brittany: Considerable diversity in mycosporine-like amino acids (MAAs). Mar. Environ. Res. 2019, 147, 37-48, https://doi.org/10.1016/j.marenvres.2019.04.001.

17. Pathak, J.; Pandey, A.; Maurya, P.K.; Rajneesh, R.; Sinha, R.P.; Singh, S.P. Cyanobacterial Secondary Metabolite Scytonemin: A Potential Photoprotective and Pharmaceutical Compound. Proceedings of the National Academy of Sciences, India Section B: Biological Sciences 2020, 90, 467-481, https://doi.org/10.1007/s40011-019-01134-5. 
18. Farkas, E.; Biró, B.; Szabó, K.; Veres, K.; Zs, C.; Engel, R. The amount of lichen secondary metabolites in Cladonia foliacea (Cladoniaceae, lichenised Ascomycota). Acta Botanica Hungarica Acta Botanica Hungarica 2020, 62, 33-48, https://doi.org/10.1556/034.62.2020.1-2.4.

19. Nguyen, T.T.T.; Chollet-Krugler, M.; Lohézic-Le Dévéhat, F.; Rouaud, I.; Boustie, J. Mycosporine-like compounds in chlorolichens: isolation from Dermatocarpon luridum and Dermatocarpon miniatum, and their photoprotective properties. Planta Medica Letters 2015, 2, e1-e5, https://doi.org/10.1055/s-0034-1396321.

20. Rancan, F.; Rosan, S.; Boehm, K.; Fernández, E.; Hidalgo, M.E.; Quihot, W.; Rubio, C.; Boehm, F.; Piazena, H.; Oltmanns, U. Protection against UVB irradiation by natural filters extracted from lichens. J. Photochem. Photobiol. B: Biol. 2002, 68, 133-139, https://doi.org/10.1016/s1011-1344(02)00362-7.

21. Fernández, E.; Quilhot, W.; Rubio, C.; Hidalgo, M.E.; Diaz, R.; Ojeda, J. Effects of UV Radiation on Usnic Acid in Xanthoparmelia microspora (Müll. Arg. Hale). Photochem. Photobiol. 2006, 82, 1065-1068, https://doi.org/10.1562/2006-01-19-RA-782.

22. Khader, S.Z.A.; Ahmed, S.S.Z; Arunachalam, T.; Radhakrishnan, K. Therapeutic effect of Parmotrema tinctorum against complete Freund's adjuvant-induced arthritis in rats and identification of novel Isophthalic ester derivative. Biomed Pharmacother. 2019, 112, 108646, https://doi.org/10.1016/j.biopha.2019.108646.

23. Tomović, J.; Kosanić, M.; Ranković, B.; Vasiljević, P.; Najman, S.; Manojlović, N. Phytochemical analysis and biological activity of extracts of lichen Physcia Semipinnata: As a new source of pharmacologically active compounds. Farmacia 2019, 67, 346-353, https://doi.org/10.31925/farmacia.2019.2.21.

24. Maulidiyah, M.; Darmawan, A.; Hasan, A.; Wibowo, D.; Salim, L.O.A.; Ansharullah, A.; Mustapa, F.; Nurdin, I.F.A.; Nurdin, M. Isolation, structure elucidation, and antidiabetic test of vicanicin compound from lichen Teloschistes flavicans. J Appl Pharm Sci. 2020, 10(11), 001-009, https://doi.org/10.7324/JAPS.2020.10111.

25. Legouin, B.; Dévéhat, L.-L.; Ferron, S.; Rouaud, I.; Le Pogam, P.; Cornevin, L.; Bertrand, M.; Boustie, J. Specialized metabolites of the lichen Vulpicida pinastri act as photoprotective agents. Molecules 2017, 22, 1162, https://doi.org/10.3390/molecules22071162.

26. Diffey, B.L.; Robson, J. A new substrate to measure sunscreen protection factors throughout the ultraviolet spectrum. J. Soc. Cosmet. Chem. 1989, 40, 127-133.

27. Diffey, B. Spectral uniformity: a new index of broad spectrum (UVA) protection. Int. J. Cosmetic Sci. 2009, 31, 63-68, https://doi.org/10.1111/j.1468-2494.2008.00471.x.

28. Diffey, B.L.; Brown, M.W. The Ideal Spectral Profile of Topical Sunscreens. Photochem. Photobiol. 2012, 88, 744-747, https://doi.org/10.1111/j.1751-1097.2012.01084.x.

29. Lohézic-Le Dévéhat, F.; Legouin, B.; Couteau, C.; Boustie, J.; Coiffard, L. Lichenic extracts and metabolites as UV filters. J. Photochem. Photobiol. B: Biol. 2013, 120, 17-28, http://dx.doi.org/10.1016/j.jphotobiol.2013.01.009.

30. Pavan Kumar, P.; Siva, B.; Anand, A.; Tiwari, A.K.; Vekata Rao, C.; Boustie, J.; Suresh Babu, K. Isolation, semi-synthesis, free-radicals scavenging, and advanced glycation end products formation inhibitory constituents from Parmotrema tinctorum. J. Asian Nat. Prod. Res. 2020, 22, 976-988, https://doi.org/10.1080/10286020.2019.1628024.

31. Tuan, N.T.; Dam, N.P.; Van Hieu, M.; Trang, D.T.X.; Danh, L.T.; Men, T.T.; De, T.Q.; Bach, L.T.; Kanaori, K. Chemical Constituents of the Lichen Parmotrema Tinctorum and their Antifungal Activity. Chem. Nat. Compd. 2020, 56, 315-317, https://doi.org/10.1007/s10600-020-03017-y.

32. Tram, N.T.T.; Huyen, V.T.; Pascal, R. Study on chemical constituents of the lichen Parmotrema tinctorum (Nyl.) Hale. Vietnam Journal of Science and Technology 2018, 56, 434, https://doi.org/10.15625/2525$2518 / 56 / 4 / 11638$. 